Journal of Patient-Centered

$1-17-2022$

\title{
Patient Satisfaction With Care Is Associated With Better Outcomes in Function and Pain 1 Year After Lumbar Spine Surgery
}

\author{
Björn Knutsson \\ Bakir Kadum \\ Ted Eneqvist \\ Sebastian Mukka \\ Arkan S. Sayed-Noor
}

Follow this and additional works at: https://aah.org/jpcrr

Part of the Health Services Research Commons, Musculoskeletal Diseases Commons, Orthopedics Commons, Rehabilitation and Therapy Commons, Surgery Commons, and the Surgical Procedures, Operative Commons

\section{Recommended Citation}

Knutsson B, Kadum B, Eneqvist T, Mukka S, Sayed-Noor AS. Patient satisfaction with care is associated with better outcomes in function and pain 1 year after lumbar spine surgery. J Patient Cent Res Rev. 2022;9:7-14. doi: 10.17294/2330-0698.1883

Published quarterly by Midwest-based health system Advocate Aurora Health and indexed in PubMed Central, the Journal of Patient-Centered Research and Reviews (JPCRR) is an open access, peer-reviewed medical journal focused on disseminating scholarly works devoted to improving patient-centered care practices, health outcomes, and the patient experience. 


\title{
Patient Satisfaction With Care Is Associated With Better Outcomes in Function and Pain 1 Year After Lumbar Spine Surgery
}

\author{
Björn Knutsson, MD, PhD, ${ }^{1}$ Bakir Kadum, MD, PhD, ${ }^{2}$ Ted Eneqvist, MD, $\mathrm{PhD},{ }^{3}$ Sebastian Mukka, \\ $\mathrm{MD}, \mathrm{PhD},{ }^{1}$ Arkan S. Sayed-Noor, MD, $\mathrm{PhD}^{3}$ \\ ${ }^{1}$ Department of Surgical and Perioperative Sciences, Orthopedics, Umeå University, Umeå, Sweden; ${ }^{2}$ Department of \\ Clinical and Experimental Medicine, Linköping University, Linköping, Sweden; ${ }^{3}$ Department of Clinical Science and \\ Education, Södersjukhuset, Karolinska Institute, Stockholm, Sweden
}
Purpose
There has been increasing interest in patient-reported experience measures (PREMs) to evaluate the patient experience and satisfaction with care. We conducted a prospective multicenter cohort study to determine any association between patients' satisfaction of care and their outcomes 1 year after lumbar spine surgery.
Methods Satisfaction with care was recorded through telephone interviews and a standardized questionnaire. Baseline data collection (300 patients) and 1-year follow-up (209 patients) were conducted through The Swedish National Register for Spine Surgery (Swespine). Exposures were patient experiences, health care professional (HCP) attitudes, shared decision-making, and overall satisfaction with care. Associations were evaluated using adjusted analysis of covariance (ANCOVA) models.

Results

Satisfaction with HCP attitudes was not associated with improvements at 1 year in Oswestry Disability Index (ODI) or back pain; however a significantly greater improvement in leg pain score was reported by patients who were highly satisfied (3.0 points) versus the moderate/low satisfaction group (1.3 points; $P=0.008)$. For shared decision-making, high satisfaction was associated with significantly greater improvements, as compared to moderate/low satisfaction, in ODI (20 vs 11 points; $P=0.001$ ), back pain (2.6 vs 1.7 points; $P=0.05$ ), and leg pain (3.2 vs 1.9 points, $P=0.007$ ). Similarly, high overall satisfaction with care was associated with significantly greater improvements in ODI (18 vs 10 points; $\mathrm{P}=0.02$ ), back pain (3.2 vs 0.6 points; $\mathrm{P}<0.001$ ), and leg pain (2.6 vs 1.1 points; $\mathrm{P}=0.009$ ).

Conclusions Findings indicate that shared decision-making on perioperative care and patients' overall satisfaction with care were associated with better health outcomes 1 year after lumbar spine surgery. (J Patient Cent Res Rev. 2022;9:7-14.)

Keywords patient satisfaction; patient experience; shared decision-making; patient-reported outcomes; PROMs; PREMs; patient-centered care

$\mathrm{S}$ urgery for degenerative disease in the lumbar spine is common, and the number of surgical procedures is continuously on the rise in both Europe and the United States. ${ }^{1,2}$ In recent decades, these procedures have been evaluated using patient-reported outcome measures (PROMs). Valid PROMs such as the Oswestry Disability Index (ODI), EuroQoL's EQ-5D score, Visual Analogue Scale, and Numeric Rating Scale (NRS)

Corresponding author: Arkan S. Sayed-Noor, Department of Clinical Science and Education, Södersjukhuset, Karolinska Institute, 17177 Stockholm, Sweden (arkan.s.sayednoor@ki.se) measure function, quality of life, and pain - important parameters for evaluating surgical procedures from a patient perspective. ${ }^{3,4}$ However, these PROMs do not capture the patient experience of receiving care, and there has been an increased interest in obtaining patientreported experience measures (PREMs) to evaluate a patient's level of satisfaction with care..$^{5,6}$

Using satisfaction as a quality metric in general is controversial, as patients may not be equipped to know what should really drive their care or the complexities of health care coordination. ${ }^{5}$ Overall satisfaction is used to evaluate both outcomes after surgery and the patient experience. ${ }^{7}$ Like PROMs, PREMs can be more specific in capturing a specific experience of care, such as the 
attitudes of health care professionals (HCP) as perceived by patients and the involvement of shared decisionmaking (SDM).

SDM is a process in which clinicians actively involve patients in their care. In spine surgery, most studies focus on involving the patient in making the decision regarding surgery. ${ }^{8,9}$ However, SDM is not a clear-cut concept and could also more subtly impact quality of care through patients' individual feelings on degree of decisionmaking involvement or their preferences regarding $\mathrm{HCP}$ patient interaction. $8,10,11$

Earlier studies in elective lumbar spine surgery focused on outcomes measured using PROMs and patients' satisfaction with treatment. Only a few studies have focused on patient experience of care and its association with outcomes, and knowledge regarding the association between PREMs and PROMs in spine surgery is limited. ${ }^{12,13}$ Therefore, we performed a multicenter prospective study to evaluate potential associations between patients' experiences of care (including $\mathrm{HCP}$ attitudes, SDM, and overall satisfaction with care) and outcomes 1 year after lumbar spine surgery, hypothesizing that such associations would prove to be significant. The primary outcome was improvement in ODI between inclusion and the 1-year follow-up. Secondary outcomes were improvements in back and leg pain on the NRS.

\section{METHODS}

\section{Data Source}

The Swedish National Register for Spine Surgery (Swespine) is a prospective registry of patients who have undergone surgery for spinal disorders in Sweden. ${ }^{14,15}$ Patients complete a preoperative questionnaire that includes questions about age, sex, smoking status (current/no smoking), previous back surgery (yes/no), ODI, and back and leg pain measured on the NRS. The surgeon records surgical data, including diagnosis, surgical procedure, and any complications. Follow-up postal questionnaires at $1,2,5$, and 10 years after surgery are sent to patients along with a prepaid addressed return envelope.

\section{Patients}

This study was approved by the local regional ethical board. Data were collected through collaboration between Swespine and survey company Indikator, which included an evaluation of care experiences from patients making up Swespine 2014. ${ }^{16,17}$ From September 1, 2015, to October 14, 2015, 300 consecutive patients from Swespine were recruited for the study. During the study period, Indikator was informed when a patient with an elective procedure for the lumbar spine was registered in Swespine. Professional interviewers contacted the patients on the phone and asked for informed consent to be included in our study; all agreed to participate.

The median value between discharge and interview was 35 days (range: 24-61). Interviews followed a specific questionnaire unrelated to Swespine and are described in detail in the ensuing subsection. One year after surgery, the patients received the standard follow-up questionnaire from Swespine. Our study's inclusion criteria were ability to speak Swedish, age between 18 and 90 years, and diagnosis and surgical procedure in the lumbar spine registered in Swespine, Figure 1 shows a flow diagram of the study population.

300 continuous patients included from Swespine between September 1, 2015, and October 14, 2015

All 300 patients agreed to participate in the study; they were interviewed, on average, 5 weeks after surgery

209 of $300(70 \%)$ fullfilled the 1-year follow-up in Swespine

Figure 1. Flowchart for inclusion in the study.

\section{Questionnaire}

The questionnaire used in this study was constructed and evaluated by Indikator in dialog with the first author (B.K.). The questionnaire started with informed consent, followed by 23 items in total, including questions about sociodemographic and medical information. Seven questions were designed to capture three dimensions of care: patients' experience of care regarding HCP attitudes, SDM, and overall satisfaction with care (Figure 2). These dimensions were dichotomized into high or moderate/ low satisfaction. 


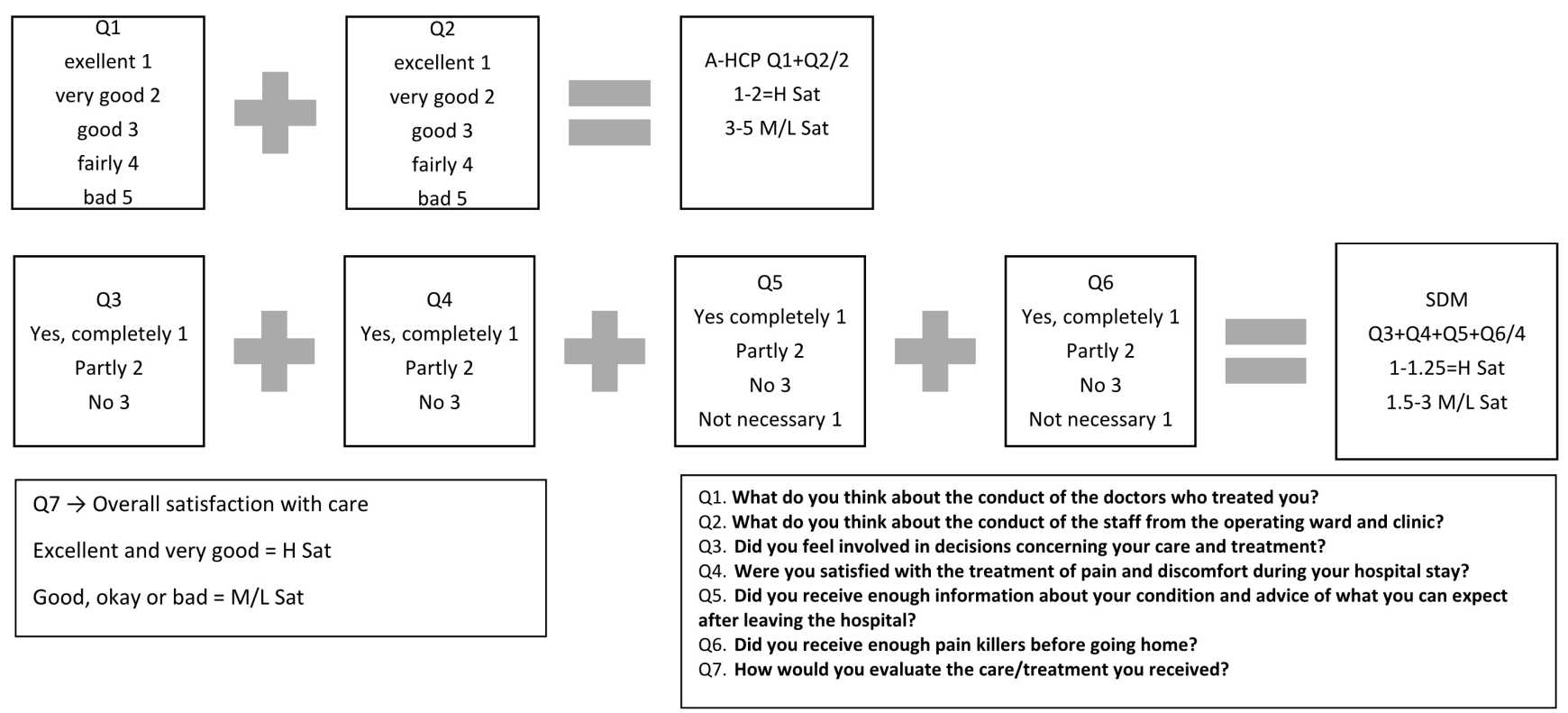

Figure 2. The questions (Q1-Q7) created three dimensions: attitudes from health care professionals $(A-H C P)$, shared decision-making (SDM), and overall satisfaction with care. Numbers behind the answers are added to a sum, which was divided by the number of questions included in the variable. Answers were dichotomized into high $(H)$ or moderate/low (M/L) satisfaction (Sat).

\section{Outcome Measures}

Functional status was assessed using the ODI, which is a disease-specific functional questionnaire. ${ }^{4}$ It consists of 10 items that assess limitations in daily activities (pain intensity, personal care, lifting, walking, sitting, standing, sleeping, sex life, social life, and traveling). Each question has 5 points, and the summary is converted into a percentage scored from 0 to 100 ; higher scores indicate more severe symptoms: $0-20=$ minimal disability, $21-40$ $=$ moderate disability, $41-60=$ severe disability, $61-80=$ crippled, $81-100=$ patient bedbound. The ODI has been validated and adapted to Swedish culture. ${ }^{18}$

The NRS is a well-validated instrument for unidimensional assessment of pain ${ }^{3}$ that asks patients to rate their pain on a scale from 0 (no pain) to 10 (worst possible pain).

\section{Statistical Analysis}

Initially, the internal consistency of the 7 questions was tested, resulting in a Cronbach's alpha of 0.75 . The dependent variables ODI and NRS were analyzed as continuous variables and as improvement from inclusion to follow-up. Multiple tests were used to confirm data were normal before applying parametric methods. A histogram confirmed normal distribution for both ODI and NRS; a normal P-P plot confirmed normally distributed residuals; and Shapiro-Wilk and Levene tests confirmed normal distribution and variance homogeneity for the outcomes. Finally, the homogeneity of regression slopes was checked. Analyses of covariance (ANCOVA) models were adjusted for age, gender, smoking, previous back surgery, and baseline value for the variable studied (P-value alpha of 0.05).

\section{RESULTS}

A total of 209 (70\%) patients completed the 1-year followup. All surgeries were done as elective lumbar spine procedures at 25 different orthopedic or neurosurgical clinics. The majority of patients had lumbar spinal stenosis $(\mathrm{n}=150,72 \%)$, while a minority had disc prolapse $(\mathrm{n}=24,11 \%)$, chronic low-back pain $(\mathrm{n}=17,8 \%)$, isthmic spondylolisthesis $(n=11,5 \%)$, and other diagnoses $(n=7$, $3 \%$ ). Mean age at inclusion was 64 (standard deviation [SD]: 15) years, and 54\% of participants were women. Further details on patient characteristics at baseline are described in Table 1.

Most of the 209 patients included in the final analysis reported high satisfaction with $\mathrm{HCP}$ attitudes, SDM, and overall satisfaction. Results from the 7-item questionnaire are described in Table 2. On average, the mean improvement in ODI from inclusion to 1-year follow-up was 18 points (SD: 19) points. Mean improvements in NRS for back pain and leg pain were 2.5 (SD: 3.0 ) and 2.9 (SD: 3.5) points, respectively. 
Table 1. Characteristics at Baseline for Study Participants Who Also Completed 1-Year Follow-Up

\begin{tabular}{lc}
\hline Characteristic & $\mathbf{N}=\mathbf{2 0 9}$ \\
\hline Sex, $\mathrm{n}(\%)$ & $114(54 \%)$ \\
Female & $95(46 \%)$ \\
Male & \\
Smoking, $\mathrm{n}(\%)$ & $198(95 \%)$ \\
No & $11(5 \%)$ \\
Current & \\
Previous surgery, $\mathrm{n}(\%)$ & $41(20 \%)$ \\
Yes & $168(80 \%)$ \\
No & $64(14)$ \\
Age in years, mean (SD) & $43(16)$ \\
Oswestry Disability Index, mean (SD) & $6.0(2.5)$ \\
Back pain rating on NRS, mean (SD) & $6.4(2.5)$ \\
Leg pain rating on NRS, mean (SD)
\end{tabular}

NRS; Numeric Rating Scale; SD, standard deviation.
Attitudes of HCP

Patients who were highly satisfied with HCP attitudes showed a mean improvement in ODI of 18 (95\% CI: 1621) points, whereas the moderate/low satisfaction group improved by 13 (95\% CI: 6-20) points, a nonsignificant difference $(\mathrm{P}=0.17)$. There was no significant difference between the groups in improvement in back pain $(2.5$ points [95\% CI: 2.1-2.9] in high satisfaction group vs 1.7 points [95\% CI: $0.6-2.7]$ in moderate/low satisfaction group; $\mathrm{P}=0.16$ ). On the other hand, the difference in leg pain improvement was statistically significant, with the high satisfaction group reporting an improvement of 3.0 points (95\% CI: $2.6-3.5)$ compared to 1.3 points $(95 \%$ CI: $0.1-2.5)$ for the moderate/low satisfaction group $(\mathrm{P}=0.008)$ (Table 3).

\section{Shared Decision-Making}

The mean improvement in ODI for the group highly satisfied with the SDM aspect of their care was $20(95 \%$

Table 2. The 7 Standardized Questions Used in the Study and Respective Results From the 209

Patients Who Completed the 1-Year Follow-Up

Q1. What do you think about the conduct of the physicians who treated you?

\begin{tabular}{|c|c|c|c|c|c|}
\hline Excellent & Very good & Good & Fair & Bad & Missing data \\
\hline $\mathrm{n}=128(61 \%)$ & $\mathrm{n}=55(26 \%)$ & $\mathrm{n}=20(10 \%)$ & $\mathrm{n}=3(1 \%)$ & $\mathrm{n}=2(1 \%)$ & $\mathrm{n}=1(1 \%)$ \\
\hline
\end{tabular}

Q2. What do you think about the conduct of the staff from the operation ward and the clinic?

\begin{tabular}{|c|c|c|c|}
\hline Excellent & Very good & Good & Fair \\
\hline $\mathrm{n}=138(66 \%)$ & $\mathrm{n}=58(28 \%)$ & $\mathrm{n}=10(5 \%)$ & $\mathrm{n}=3(1 \%)$ \\
\hline
\end{tabular}

Q3. Did you feel involved in decisions concerning your care and treatment?

\begin{tabular}{|c|c|c|c|}
\hline Yes, completely & Partly & No & Missing data \\
\hline $\mathrm{n}=175(84 \%)$ & $\mathrm{n}=30(14 \%)$ & $\mathrm{n}=2(1 \%)$ & $\mathrm{n}=2(1 \%)$ \\
\hline
\end{tabular}

Q4. Were you satisfied with the treatment of pain and discomfort during your hospital stay?

\begin{tabular}{|c|c|c|}
\hline Yes, completely & Partly & No \\
\hline $\mathrm{n}=179(86 \%)$ & $\mathrm{n}=25(12 \%)$ & $\mathrm{n}=5(2 \%)$ \\
\hline
\end{tabular}

Q5. Did you receive enough information about your condition and advice of what you can expect after leaving the hospital?

\begin{tabular}{|c|c|c|c|}
\hline Yes, completely & Partly & No & It was not necessary \\
\hline $\mathrm{n}=138(65 \%)$ & $\mathrm{n}=57(27 \%)$ & $\mathrm{n}=9(4 \%)$ & $\mathrm{n}=5(2 \%)$ \\
\hline
\end{tabular}

Q6. Did you receive enough painkillers before going home?

\begin{tabular}{|c|c|c|c|}
\hline Yes, completely & Partly & No & It was not necessary \\
\hline $\mathrm{n}=181(87 \%)$ & $\mathrm{n}=15(7 \%)$ & $\mathrm{n}=3(1 \%)$ & $\mathrm{n}=10(5 \%)$ \\
\hline
\end{tabular}

Q7. How would you evaluate the care/treatment you received?

\begin{tabular}{|c|c|c|c|c|}
\hline Excellent & Very good & Good & Fair & Bad \\
\hline $\mathrm{n}=136(65 \%)$ & $\mathrm{n}=49(23 \%)$ & $\mathrm{n}=19(9 \%)$ & $\mathrm{n}=3(1 \%)$ & $\mathrm{n}=2(1 \%)$ \\
\hline
\end{tabular}


Table 3. Improvement Between Study Inclusion and 1-Year Follow-Up

\begin{tabular}{|c|c|c|c|}
\hline Dimension of care & $\begin{array}{c}\text { ODI } \\
\text { improvement* }\end{array}$ & $\begin{array}{l}\text { Improvement in back } \\
\text { pain on NRS* }\end{array}$ & $\begin{array}{l}\text { Improvement in leg } \\
\text { pain on NRS* }\end{array}$ \\
\hline \multicolumn{4}{|l|}{ HCP attitudes } \\
\hline High satisfaction & $\mathrm{n}=186 ; \uparrow 18 ; 16-21$ & $\mathrm{n}=175 ; \uparrow 2.5 ; 2.1-2.9$ & $\mathrm{n}=178 ; \uparrow 3.0 ; 2.6-3.5$ \\
\hline Moderate/Low satisfaction & $\mathrm{n}=23 ; \uparrow 13 ; 6-20$ & $\mathrm{n}=24 ; \uparrow 1.7 ; 0.6-2.7$ & $\mathrm{n}=24 ; \uparrow 1.3 ; 0.1-2.5$ \\
\hline$P$ & 0.17 & 0.16 & 0.008 \\
\hline \multicolumn{4}{|l|}{ Shared decision-making } \\
\hline High satisfaction & $\mathrm{n}=159 ; \uparrow 20 ; 17-22$ & $\mathrm{n}=149 ; \uparrow 2.6 ; 2.2-3.1$ & $\mathrm{n}=151 ; \uparrow 3.2 ; 2.7-3.6)$ \\
\hline Moderate/Low satisfaction & $\mathrm{n}=50 ; \uparrow 11 ; 6-15$ & $\mathrm{n}=50 ; \uparrow 1.7 ; 1.0-2.5$ & $\mathrm{n}=51 ; \uparrow 1.9 ; 1.1-2.7$ \\
\hline$P$ & 0.001 & 0.05 & 0.007 \\
\hline \multicolumn{4}{|l|}{ Overall satisfaction } \\
\hline High satisfaction & $\mathrm{n}=185 ; \uparrow 18 ; 16-21$ & $\mathrm{n}=175 ; \uparrow 3.2 ; 2.8-3.6$ & $\mathrm{n}=172 ; \uparrow 2.6 ; 2.2-3.0$ \\
\hline Moderate/Low satisfaction & $\mathrm{n}=24 ; \uparrow 10 ; 3-17$ & $\mathrm{n}=24 ; \uparrow 0.6 ;-0.6-1.7$ & $\mathrm{n}=24 ; \uparrow 1.1 ; 0.3-2.2$ \\
\hline$P$ & 0.02 & $<0.001$ & 0.009 \\
\hline
\end{tabular}

*Values are presented as number of patients in group; change in mean score at 1 year; 95\% Cl. Associations were analyzed using ANCOVA, with means adjusted for age, gender, smoking, earlier back surgery, and the baseline value for the variable studied. P-values represent the difference between subgroups within each dimension, with significance level of 0.05 .

HCP, health care professional; NRS, Numeric Rating Scale; ODI, Oswestry Disability Index.

CI: 17-22) points, while the moderate/low satisfaction group improved by $11(95 \% \mathrm{CI}: 6-15)$ points $(\mathrm{P}=0.001)$. Less significantly, back pain rating improved by $2.6(95 \%$ CI: $2.2-3.1)$ vs 1.7 (95\% CI: $1.0-2.5)$ points in high vs moderate/low groups $(\mathrm{P}=0.05)$, respectively, and leg pain rating improved by 3.2 (95\% CI: $2.7-3.6)$ vs 1.9 (95\% CI: $1.1-2.7)$ points in high vs moderate/low groups $(\mathrm{P}=0.007)$, respectively (Table 3 ).

\section{Overall Satisfaction}

A high overall satisfaction with care was associated with significantly greater improvements in ODI $(\mathrm{P}=0.02)$, back pain $(\mathrm{P}<0.001)$, and leg pain $(\mathrm{P}=0.009)$. Specifically, patients with high overall satisfaction reported an improvement of 18 (95\% CI: 16-21) points in the ODI, whereas patients with moderate/low overall satisfaction improved by 10 (95\% CI: 3-17) points. Back pain improved by 3.2 (95\% CI: $2.8-3.6)$ points for the high satisfaction group and by 0.6 (95\% CI: $-0.6-1.7)$ points for the moderate/low satisfaction group, and leg pain improved by 2.6 (95\% CI: $2.2-3.0)$ vs 1.1 (95\% CI: $0.3-2.2$ ) points, respectively (Table 3 ).

\section{Lost-to-Follow-Up Analysis}

As a sensitivity analysis for these results, a lost-to-followup analysis comparing baseline data at inclusion for patients who were lost to follow-up $(n=91)$ with those who completed the study $(n=209)$ was performed. One significant difference was found: patients lost to follow-up were less satisfied with SDM, with $65 \%$ of the patients lost to follow-up reporting high satisfaction with SDM vs $83 \%$ high satisfaction with SDM among patients who completed follow-up $(\mathrm{P}=0.001)$. No significant differences were found in age $(\mathrm{P}=0.06)$, gender $(\mathrm{P}=0.36)$, smoking status $(\mathrm{P}=0.51)$, previous back surgery $(\mathrm{P}=0.72)$ or baseline values of the outcomes ( $\mathrm{P}=0.90$ for ODI; $\mathrm{P}=0.19$ for back pain NRS; and $\mathrm{P}=0.13$ for leg pain NRS). Furthermore, loss to follow-up was not related to patient reports of $\mathrm{HCP}$ attitudes $(\mathrm{P}=0.24)$ or overall satisfaction with care $(\mathrm{P}=0.10)$.

\section{DISCUSSION}

The results of this prospective multicenter study demonstrate that a high level of patient satisfaction with SDM and overall satisfaction with care is associated with statistically significantly better improvement in function, back pain, and leg pain as compared to patients who were less satisfied with SDM and their perioperative care. Although our study design does not support any causality, the association between PREMs and outcomes is discussed hereinafter.

There is still limited evidence about whether HCP attitudes are associated with outcomes after lumbar spine surgery. Rabah et al found no association between physicians' communication and outcomes in quality of life, function, or pain. ${ }^{12}$ The study was retrospective in design and included 479 patients. Follow-ups were conducted at 3 months and 1 year. Another retrospective study from Rabah et al found a link between high satisfaction with the surgeon and improvement in back pain, but no 
significant improvement in physical or mental function correlated with PREMs. The authors concluded that an association in 1 of 3 outcomes could not be regarded as a clinically important finding. ${ }^{13}$ Our results regarding HCP attitudes were similar, as we found a significant difference in improvement in leg pain but not in back pain or ODI.

Although several studies have discussed the importance of SDM in general, including patients with an orthopedic diagnosis, only a few correlate SDM to outcomes in spine surgery. Andersen et al argued that SDM can be helpful in surgical treatment decisions for lumbar disc herniation. ${ }^{9}$ Video programs, booklets, and online information are reported as important tools in the SDM process, and several interactive methods are described for SDM. However observed or measured, it is not necessarily the same thing as the SDM experienced. Mertz et al stated that a patient's perceived SDM is correlated weakly with objective SDM. ${ }^{19}$ The patients in our study reported a high perceived SDM, which is probably not solely due to care experiences in the hospital. In Sweden, patient-centered care is statutory, and the health system is available for all citizens. Furthermore, patients can choose their caregivers, even within public health care. All patients have full access to their medical records online. Another source of information is Swespine, in which more than $80 \%$ of all spine surgeries in Sweden are included and annual reports/results are published online. ${ }^{15}$ All of these factors encourage patients to take a more active role in their treatment and perhaps increase their perception of involvement and SDM. The questionnaire in our study is more about perceived SDM, and it is perhaps perceived SDM that is the most important for correlation with outcomes after surgery.

The concept of patient satisfaction with care is not fully understood. A systematic review concluded that patient satisfaction with care included 7 dimensions (pain, function, patients' experience or preferences, specific health characteristics, caregivers' interpersonal manners, efficacy/clinical outcomes, and postoperative care/ therapy)..$^{5}$ Our finding of overall satisfaction's association with better outcomes are consistent with those of Jha et al, ${ }^{6}$ who analyzed data from 2429 hospitals and found a correlation between high satisfaction with care and patients' experiences of care in U.S. hospitals. ${ }^{6}$ That study also found a correlation between patient satisfaction with care and moderately higher quality of care in surgery, pneumonia, heart failure, and acute myocardial infarction. Glickman et al studied 6467 patients with myocardial infarction and found an association between overall satisfaction and survival..$^{20}$ In contrast, several other studies have not found any association between overall satisfaction and outcomes. ${ }^{21-23}$

\section{Limitations}

The strengths of our study include its multicenter prospective study design and method of data collection. Both the interviews and follow-ups through Swespine were conducted without any influence of HCP. Additionally, the questionnaire used showed good internal consistency. However, our study has some limitations. For one, data came from a single country so results may lack generalizability outside of Sweden. Our categorization of the patient experience is a conceivable limitation. There are different methods to measure and define our categories of exposure, and another measure/definition of exposure could possibly change our results. Because we performed our study in collaboration with survey company Indikator, which has immense experience in these kinds of studies and research questions, we consider our interpretation of the questionnaire as representative for the context given in the method section. Similar to earlier studies on patients who underwent spine surgery, patients in our study reported excellent or particularly good experiences of care. ${ }^{12,13} \mathrm{Few}$ patients were dissatisfied with their treatment, and the unequal sample sizes may affect the results.

Another limitation is the loss to follow-up, as $30 \%$ of the patients did not complete the 1-year follow-up. We performed lost-to-follow-up analysis and compared the baseline data at inclusion of patients who were lost to follow-up with those who completed the study. Although the loss to follow-up may have affected our results, the response rate was not related to SDM. In addition, a register study on lumbar surgery found no differences between responders and nonresponders in PROMs at a 2 -year follow-up. ${ }^{24}$ Thus, we believe the 209 respondents are representative of the 300 patients included at baseline.

Assessing patient experience of care at different time points may provide different results. For practical and logistic reasons, we chose to conduct the interviews 1-2 months after surgery. Earlier studies showed acceptable variability in responses regarding patients' satisfaction between 2 weeks and 3 months. ${ }^{25}$ The short follow-up is another possible limitation; however, earlier studies on spine surgery have shown comparable results in short- and long-term follow-up. ${ }^{26,27}$ Therefore, we consider our 1-year results to be reliable and probably consistent with the long-term results. Lastly, we did not look at the influence of psychosocial factors, such as depression, on degree of satisfaction and surgical outcomes. ${ }^{28}$ This possible association should be considered in future studies.

\section{CONCLUSIONS}

Study findings indicate that patients' perceived shared decision-making in perioperative care and overall satisfaction with care are plausible explanations for the better outcomes reported 1 year after lumbar spine 
surgery. Whether higher perceived SDM and overall satisfaction can further improve results after spine surgery remains to be established.

\section{Patient-Friendly Recap}

- The perceived quality of a patient's health care experience may impact orthopedic outcomes.

- In this prospective study, authors used survey questions and clinical data to determine if patients' satisfaction with aspects of their spine surgery experience correlated to back or leg function/pain measured 1 year later.

- Patients who reported shortly after the surgery that they were highly satisfied with the shared decisionmaking process and had high overall satisfaction with the care provided showed significantly greater improvements in function and pain at 1-year follow-up.

- Degree of satisfaction with attitudes of health care professionals was not associated with better or worse outcomes.

\section{Acknowledgments}

The authors acknowledge Karin Tidlund, Laith N. Hussain, and Ida Låstbom for their work on the study, including design of the questionnaire, telephone interviews, data collection, and initial data analysis.

\section{Author Contributions}

Study design: all authors. Data acquisition or analysis: Knutsson, SayedNoor. Manuscript drafting: all authors. Critical revision: all authors.

\section{Conflicts of Interest}

None.

\section{Funding Sources}

This work was supported by the Department of Research and Development, Västernorrland County Council, and the Swedish Association of Local Authorities and Regions (SALAR), which is an employers' organization that represents and advocates for local government in Sweden. All of Sweden's municipalities and regions are members of SALAR.

\section{References}

1. Deyo RA, Mirza SK, Martin BI, Kreuter W, Goodman DC, Jarvik JG. Trends, major medical complications, and charges associated with surgery for lumbar spinal stenosis in older adults. JAMA. 2010;303:1259-65. CrossRef

2. Jansson KA, Blomqvist P, Granath F, Németh G. Spinal stenosis surgery in Sweden 1987-1999. Eur Spine J. 2003;12:535-41. CrossRef

3. Hjermstad MJ, Fayers PM, Haugen DF, et al. Studies comparing Numerical Rating Scales, Verbal Rating Scales, and Visual Analogue Scales for assessment of pain intensity in adults: a systematic literature review. J Pain Symptom Manage. 2011;41:1073-93. $\underline{\text { CrossRef }}$
4. McCormick JD, Werner BC, Shimer AL. Patient-reported outcome measures in spine surgery. J Am Acad Orthop Surg. 2013;21:99-107. CrossRef

5. Menendez JY, Omar NB, Chagoya G, et al. Patient satisfaction in spine surgery: a systematic review of the literature. Asian Spine J. 2019;13:1047-57. CrossRef

6. Jha AK, Orav EJ, Zheng J, Epstein AM. Patients' perception of hospital care in the United States. $N$ Engl J Med. 2008;359:1921-31. CrossRef

7. Jones CH, O’Neill S, McLean KA, Wigmore SJ, Harrison EM. Patient experience and overall satisfaction after emergency abdominal surgery. BMC Surg. 2017;17(1):76. CrossRef

8. Niburski K, Guadagno E, Mohtashami S, Poenaru D. Shared decision making in surgery: a scoping review of the literature. Health Expect. 2020;23:1241-9. CrossRef

9. Andersen SB, Andersen MO, Carreon LY, Coulter A, Steffensen KD. Shared decision making when patients consider surgery for lumbar herniated disc: development and test of a patient decision aid. BMC Med Inform Decis Mak. 2019;19(1):190. CrossRef

10. Doekhie KD, Strating MMH, Buljac-Samardzic M, van de Bovenkamp HM, Paauwe J. The different perspectives of patients, informal caregivers and professionals on patient involvement in primary care teams. A qualitative study. Health Expect. 2018;21:1171-82. CrossRef

11. Stewart MA. Effective physician-patient communication and health outcomes: a review. CMAJ. 1995;152:1423-33.

12. Rabah NM, Levin JM, Winkelman RD, Morz TE, Steinmetz MP. The association between physicians' communication and patient-reported outcomes in spine surgery. Spine (Phila Pa 1976). 2020;45:1073-80. CrossRef

13. Rabah NM, Khan HA, Levin JM, Winkelman RD, Morz Te, Steinmetz MP. The association between patient rating of their spine surgeon and quality of postoperative outcome. J Neurosurg Spine. 2020 Dec 18 [Epub ahead of print]. CrossRef

14. Strömqvist B, Fritzell P, Hägg O, Jönsson B, Sandén B, Swedish Society of Spinal Surgeons. Swespine: the Swedish spine register: the 2012 report. Eur Spine J. 2013;22:953-74. CrossRef

15. National Quality Registers, The Swedish Association of Local Authorities and Regions. National quality registers. Accessed December 25, 2020. https://kvalitetsregister. se/englishpages/findaregistry/registerarkivenglish/ nationalqualityregistryforspinesurgeryswespine.2215.html

16. Indikator - The Institute for Quality Indicators. Home page. Accessed December 25, 2020. https://www.indikator.org/

17. Swedish Back Surgery Association. Annual reports - followup of back surgery. Accessed December 25, 2020. http:// www. 4s.nu/4s-f\%C3\%B6rening/\%C 3\%A 5 rsrapporterswespine-42017503

18. Hägg O, Fritzell P, Nordwall A, Swedish Lumbar Spine Study Group. The clinical importance of changes in outcome scores after treatment for chronic low back pain. Eur Spine J. 2003;12:12-20. CrossRef

19. Mertz K, Eppler S, Yao J, et al. Patient perceptions correlate weakly with observed patient involvement in decision-making in orthopaedic surgery. Clin Orthop Relat Res. 2018;476:1859-65. CrossRef

20. Glickman SW, Boulding W, Manary M, et al. Patient satisfaction and its relationship with clinical quality and inpatient mortality in acute myocardial infarction. Circ Cardiovasc Qual Outcomes. 2010;3:188-95. CrossRef 
21. Schneider EC, Zaslavsky AM, Landon BE, Lied TR, Sheingold S, Cleary PD. National quality monitoring of Medicare health plans: the relationship between enrollees' reports and the quality of clinical care. Med Care. 2001;39:1313-25. CrossRef

22. Chang JT, Hays RD, Shekelle PG, et al. Patients' global ratings of their health care are not associated with the technical quality of their care. Ann Intern Med. 2006;144:665-72. CrossRef

23. Rao M, Clarke A, Sanderson C, Hammersley R. Patients' own assessments of quality of primary care compared with objective records based measures of technical quality of care: cross sectional study. BMJ. 2006;333(7557):19. CrossRef

24. Solberg TK, Sørlie A, Sjaavik K, Nygaard ØP, Ingebrigtesen T. Would loss to follow-up bias the outcome evaluation of patients operated for degenerative disorders of the lumbar spine? Acta Orthop. 2011;82:56-63. CrossRef

25. Brédart A, Razavi D, Robertson C, et al. Timing of patient satisfaction assessment: effect on questionnaire acceptability, completeness of data, reliability and variability of scores. Patient Educ Couns. 2002;46:131-6. CrossRef
26. Lagerbäck T, Möller H, Gerdhem P. Lumbar disc herniation surgery in adolescents and young adults: a long-term outcome comparison. Bone Joint J. 2019;101-B:1534-41. CrossRef

27. Mannion A, Porchet F, Kleinstück FS, et al. The quality of spine surgery from the patient's perspective. Part 1: the Core Outcome Measures Index in clinical practice. Eur Spine J. 2009;18 Suppl 3:367-73. CrossRef

28. Adogwa O, Carr K, Fatemi P, et al. Psychosocial factors and surgical outcomes: Are elderly depressed patients less satisfied with surgery? Spine (Phila Pa 1976). 2014;39:1614-9. CrossRef

(C) 2022 Advocate Aurora Health, Inc. 